University of Nebraska - Lincoln

DigitalCommons@University of Nebraska - Lincoln

May 1978

\title{
Irradiance Response of Tall Fescue Genotypes with Contrasting Levels of Photosynthesis and Yield
}

\author{
Wallace Wilhelm \\ University of Nebraska-Lincoln, wwilhelm1@unl.edu \\ C. J. Nelson \\ USDA
}

Follow this and additional works at: https://digitalcommons.unl.edu/usdaarsfacpub

Part of the Agricultural Science Commons

Wilhelm, Wallace and Nelson, C. J., "Irradiance Response of Tall Fescue Genotypes with Contrasting Levels of Photosynthesis and Yield" (1978). Publications from USDA-ARS / UNL Faculty. 125.

https://digitalcommons.unl.edu/usdaarsfacpub/125

This Article is brought to you for free and open access by the U.S. Department of Agriculture: Agricultural Research Service, Lincoln, Nebraska at DigitalCommons@University of Nebraska - Lincoln. It has been accepted for inclusion in Publications from USDA-ARS / UNL Faculty by an authorized administrator of DigitalCommons@University of Nebraska - Lincoln. 


\title{
Irradiance Response of Tall Fescue Genotypes with Contrasting Levels of Photosynthesis and Yield ${ }^{1}$
}

\author{
W. W. Wilhelm and C. J. Nelson ${ }^{2}$
}

\begin{abstract}
The purpose of this study was to determine if genotype by irradiance interactions or genetic variation in diurnal trends of $\mathrm{CO}_{2}$ exchange rate (CER) influenced the CER. yield relationship in tall fescue (Festuca arundinacea Schreb.). Genotypes were selected in the field for high CER-high yield, high CER-low yield, low CER-high yield, and low CER-low yield. Responses of CER to photosynthetic photon flux density (PPFD) of these genotypes were determined using both growth chamber- and field-grown material. The shapes of the PPFD response curves were similar for all genotypes, and saturation occurred at approximately $1,200 \mu \mathrm{E} \mathrm{m} \mathrm{mec}^{-1}(400$ to 700 nm) under both growth conditions. In a growth chamber at 25/20 C (light/dark), all genotypes achieved near maximal CER and photorespiration within 1 hour of the beginning of the photoperiod and maintained these rates throughout the rest of the photoperiod, with high CER genotypes exhibiting about $30 \%$ higher rates than low CER genotypes. Photorespiration rates were significantly correlated $(r=0.80)$ with CER. Leaf diffusive resistance were similar for all genotypes throughout the photoperiod.

Genotypic differences did not occur in PPFD-response curves or diurnal patterns of CER. This suggests that differences in these two factors among genotypes are not the underlying cause of the poor relationship reported between short term measurements of leaf photosynthesis on recently collared leaves and forage yield. Other factors must be limiting genetic expression for CER in terms of yield.
\end{abstract}

Additional index words: Leaf diffusive resistance, Photorespiration, Diurnal trends, Festuca arundinacea Schreb., Photosynthetic photon flux density.

G ENETIC variability has been reported in tall fescue (Festuca arundinacea Schreb.) for both $\mathrm{CO}_{2}$ exchange rate (CER) of single leaves and yield (Nelson et al., 1975a). Similar findings have been reported for other cool-season perennial forage grasses (Wilson and Cooper, 1970; Carlson et al., 1971; Rhodes, 1972; Borrill et al., 1974). Although genetic variability has been found, a positive relationship between CER of single leaves and yield has not been well documented. Increased forage yield and decreased CER were associated with selection for small mesophyll cells when compared to selections made for large mesophyll cells in perennial ryegrass (Lolium perenne L.) (Wilson and Cooper, 1970). Nelson et al. (1975a) reported an inconsistent relationship between CER and yield in clonal lines of tall fescue. Individual harvest period correlation coefficients between CER and yield ranged from -0.60 to +0.60 in three field studies, but the overall correlation coefficient was nonsignificant and negative.

\footnotetext{
${ }^{1}$ Contribution from the Missouri Agric. Exp. Stn. Journal Series 7704 . Received 15 July 1977.

${ }^{2}$ Graduate assistant (now plant physiologist, Science and Education Administration-Federal Research, USDA, Lincoln, NE 68583) and professor of agronomy, Dep. of Agronomy, Univ. of Missouri-Columbia, MO 65201.
}

Canopy shading and development (Rhodes, 1973) and dry matter distribution (Treharne and Eagles, 1970) have been suggested as factors influencing the relationship between leaf photosynthesis and yield. Nelson et al. (1975a) also suggested that genotype by irradiance interactions may influence the CER-yield relationship. In addition, genetic variation in diurnal trends in CER could affect this relationship (Pallas, 1973).

We hypothesized that different yields exhibited by tall fescue genotypes having similar photosynthetic photon flux density (PPFD) - saturated CER as determined by short term, midday measurements may result from genotypic variation in the diurnal pattern of CER or the photosynthetic PPFD response curve. The rates of carbon exchange during the early and late parts of a photoperiod may not be similar as suggested by PPFD-saturated midday measurements. Therefore, the total amount of $\mathrm{CO}_{2}$ fixed throughout a photoperiod may not be equivalent for the two types of genotypes and yields would logically differ. Yield differences among genotypes with similar PPFD-saturated CER may also be explained by differences in the shape of their photosynthetic PPFD response curve. The objectives of this research were to determine whether variation in the diurnal pattern of CER or variation in PPFD response curve could be influencing the leaf photosynthesis-yield relationship among selected genotypes of tall fescue.

\section{MATERIALS AND METHODS}

Four genotypes of tall fescue were selected from field evaluations to represent high and low CER on a leaf area basis, in combination with high and low foragc yield (Table 1). Forage yield and CER (Nelson et al., 1974) were measured on three replications of 67 genotypes during 1972. Genotypes were grown as solid stands in $1.7 \times 3.7 \mathrm{~m}$ field plots as described by Nelson et al. (1975a). Cumulative yield of the first two cuttings and mean of two CER measurements during early and late June were used to select the genotypes used in the study. Differences between the high and low categories (Table 1) were significant and large enough to make meaningful comparisons. In later studies reported herein, CER's of the genotypes in the high CER category were more comparable than those presented for the field measurements in Table 1 .

Table 1. Mean $\mathrm{CO}_{2}$ exchange rate (CER) for two measurement dates and forage yield of four selected genotypes of tall fescue, 1972.

\begin{tabular}{clcc}
\hline Genotype & Source & CER & Yield \\
\hline (CER-yield) & & $\mathrm{mg} \mathrm{CO}_{2} \mathrm{dm}^{-2}$ hour $^{-1}$ & metric tons/ha \\
H-H & 'Alta' & 29.30 & 10.30 \\
H-L & Missouri pasture & 25.03 & 7.41 \\
L-H & 'Demeter' & 20.64 & 9.32 \\
L-L & 'Kenwell' & 21.27 & 7.45 \\
& L.S.D. (0.05) & 3.45 & 1.43 \\
\hline
\end{tabular}


Three vegetative tillers of each genotype were established in $10 \times 15 \mathrm{~cm}$ plastic pots filled with Mexico silt loam topsoil in four replications. Plants were allowed to grow in the greenhouse at $25 \pm 5 \mathrm{C}$ for approximately 2 months before being transferred to a controlled environment chamber with 25/20 C (light/dark) temperature and greater than $50 \%$ relative humidity. A 14-hour photoperiod of $500 \mu \mathrm{E} \mathrm{m}^{-2} \mathrm{sec}^{-1}$ PPFD was provided by cool-white fluorescent tubes and incandescent bulbs. Plants were maintained in a well watered condition and supplemented with $50 \mathrm{ml}$ of a complete nutrient solution (Epstein, 1972) each week. Plants were cut to $6 \mathrm{~cm}$ to start the experiments after a 2-week acclimatization period in the growth chamber. Pots of each genotype had about 40 tillers.

\section{Diurnal Trends}

When regrowth was 20 to $25 \mathrm{~cm}$ tall, measurements of diffusive resistance and CER in 21 and $2 \% \mathrm{O}_{2}$ were made each hour from 1 hour before the beginning of the photoperiod until 1 hour after the end of the photoperiod. The CER was measured on two newly collared leaves from each pot using infrared gas analysis and air-sealed chambers as described by Nelson et al. (1974). Leaves were placed in the air-sealed chambers only during the time CER measurements were made (approximately 10 $\mathrm{m}: \mathrm{n} /$ hour). Photorespiration (PR) was estimated by the increase in CER in 2\% $\mathrm{O}_{2}$ over that in $21 \% \mathrm{O}_{2}$ (Canvin, 1968). Photosynthetic photon flux density inside the leaf chamber was 460 $\mu \mathrm{E} \mathrm{m}^{-2} \mathrm{sec}^{-1}$. Leaf temperature was $26 \pm 1 \mathrm{C}$ during the light period and $20 \pm 2 \mathrm{C}$ during the dark period.

Leaf diffusive resistance was measured using a Lambda In. struments, Model LI-60 $0^{3}$ diffusion porometer (Kanemasu et al., 1969) on the same leaf tissue after each CER measurement. Following the last daily measurements, leaves were detached from the plant and leaf area measured.

\section{Laboratory PPFD Response}

The four genotypes, grown under growth chamber conditions described above, were used to measure CER response to varying PPFD in the laboratory. Radiation was provided by 16150 -W floodlights, filtered through $15 \mathrm{~cm}$ of running tap water, and regulated using a rheostat. A Lambda Instruments LI-170 quantum sensor ${ }^{3}$ was used to measure PPFD at the leaf surface. Rate of $\mathrm{CO}_{2}$ exchange was measured as described above, starting at a PPFD of $1,800 \mu \mathrm{E} \mathrm{m}^{-2} \mathrm{sec}^{-1}$. Leaves reached new CER equilibrium in about $10 \mathrm{~min}$, after which PPFD was reduced by increments of $200 \mu \mathrm{E} \mathrm{m} \mathrm{m}^{-2} \mathrm{sec}^{-1}$. Leaf temperatures were maintained at 29 \pm 2 C.

\section{Field PPFD Response}

Four replications of each genotype were vegetatively established in field plots $(0.5 \times 1.5 \mathrm{~m})$ during September 1973 on imperfectly drained Mexico silt loam soil at the Agronomy Research Center, Columbia, Mo. Plots had developed into a sward and were fertilized with 26,12 , and $22 \mathrm{~kg} / \mathrm{ha}$ of elemental $\mathrm{N}$, $P$, and $K$, respectively, on 16 Mar., 13 May, 21 June, and 12 Aug. 1975. Plots were cut on 21 August and plants had regrown to 25 to $30 \mathrm{~cm}$ in height when measurements were made.

Simultaneous measurements of CER (Nelson et al., 1974) and PPFD were made on six recently collared leaves/replication from 1000 to 1500 hours on 1 Oct. 1975 when intermittent cumulus clouds occurred. Assembling points allowed a response curve to be constructed for each genotype. Response curves of CER to PPFD of the four genotypes were also generated on a clear day ( 3 Oct. 1975) by placing multiple layers of cheesecloth and fiber glass screens over the air-sealed chambers during PPFD and CER measurements.

Leaf temperatures varied from 20 to $29 \mathrm{C}$ on the days of CER measurements. The degrees to which variation in temperatures affected PPFD response was probably negligible, because within one replication maximum range in leaf temperature was $3 \mathrm{C}$.

\footnotetext{
${ }^{3}$ Mention of a trademark or proprietary product does not constitute a guarantee or warranty of the product by the USDA or the Missouri Agric. Exp. Stn. and does not imply their approval to the exclusion of other products that may be suitable.
}

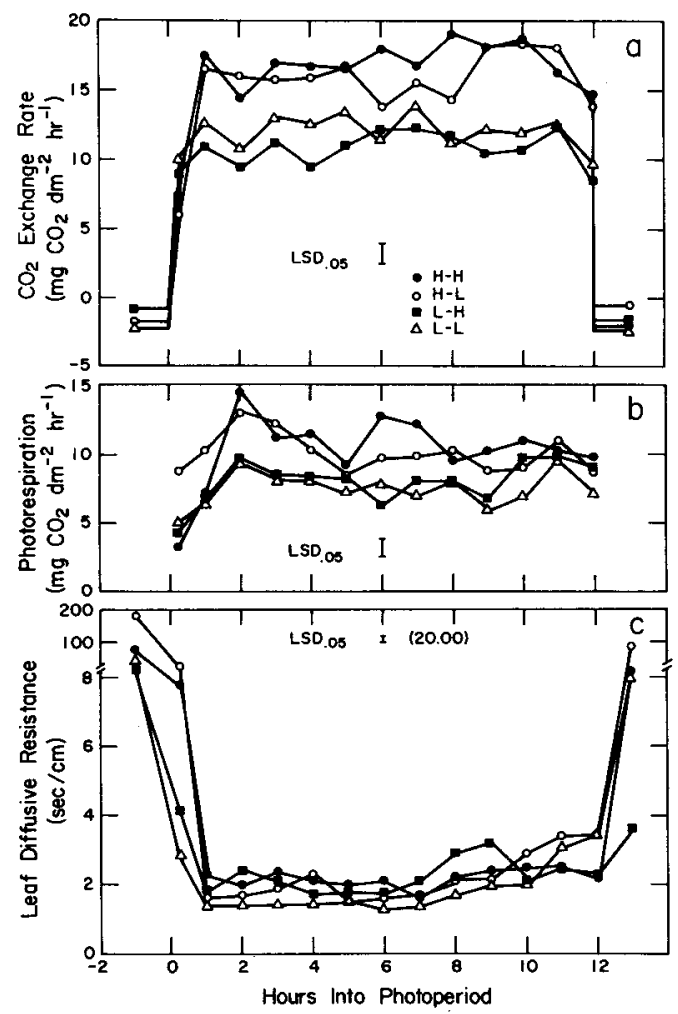

Fig. 1. Diurnal pattern of (a) $\mathrm{CO}_{2}$ exchange rate (CER), (b) photorespiration, and (c) diffusive resistance of four tall fescue genotypes with all combinations of low (L) and high (H) CER and yield levels (CER-yield).

\section{RESULTS AND DISCUSSION}

\section{Diurnal Trends}

Before the photoperiod began, the two low yielding genotypes had higher rates of dark respiration of lamina tissue than the high yielding genotypes (Fig. 1a). Low CER genotypes also had higher CER than the high CER genotypes at the first measurement during the photoperiod. Throughout the remainder of the photoperiod, however, genotypes selected for high CER maintained higher CER than low CER genotypes. Integrating the areas under the curves indicated that, during the photoperiod, $85.5,78.3,53.6$, and $66.0 \mathrm{mg}$ $\mathrm{CO}_{2} / \mathrm{dm}^{2}$ were incorporated by the $\mathrm{H}-\mathrm{H}$ (CER-yield), H-L, L-H, and L-L genotypes, respectively. After correcting for dark respiration losses in leaf tissue during the 10 hour dark period, by using the average of rates of dark respiration measured before and after the photoperiod, the daily $\mathrm{CO}_{2}$ incorporation rates into the leaf tissue were $71.8,67.1,42.4$, and $46.0 \mathrm{mg} / \mathrm{dm}^{2}$ for the H-H, H-L, L-H, and L-L genotypes, respectively. Heichel (1971) compared two cultivars of corn (Zea mays L.) which exhibited different growth rates, but similar photosynthetic rates, and found that corrections of $\mathrm{CO}_{2}$ fixation data for total plant respiration accounted for the growth differences. However, correcting for dark respiration of leaf tissue only did not account for yield differences in our study.

Rates of photorespiration (PR) were closely associated with CER (Fig. 1b). High CER genotypes ex- 


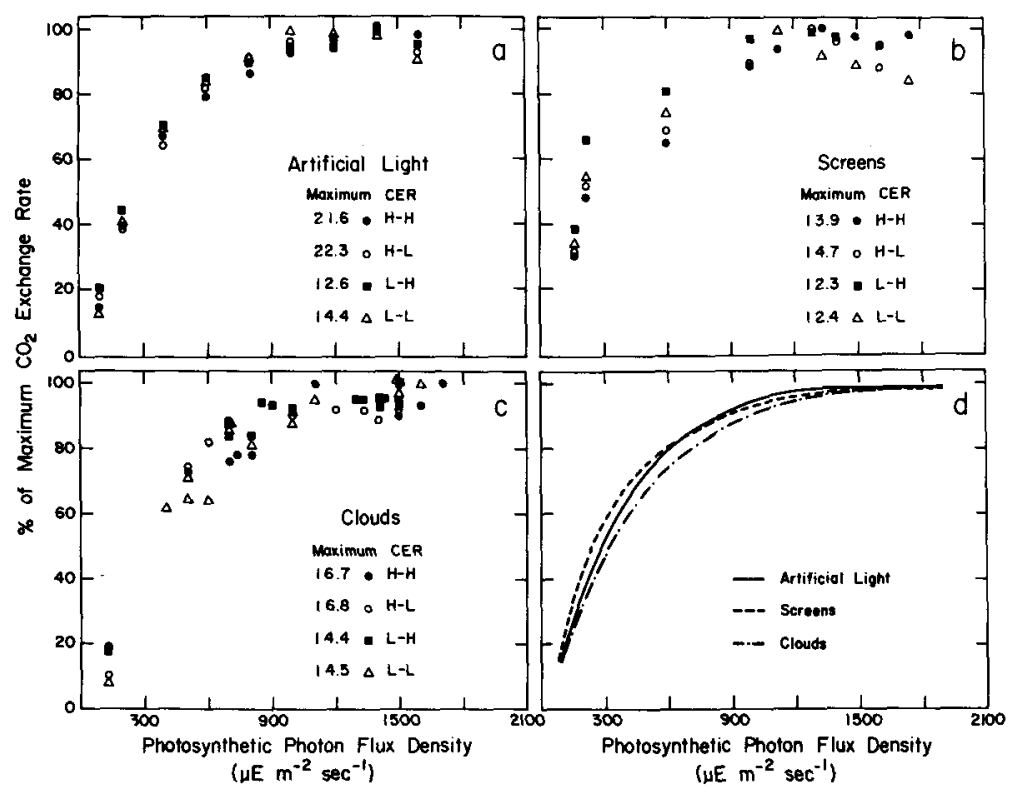

Fig. 2. Responses of $\mathrm{CO}_{2}$ exchange rate (CER) to photosynthetic photon flux density (PPFD) of four tall fescue genotypes measured (a) in the laboratory, (b) in the field with screens, (c) in the field with clouds; and (d) combined curves of the four genotypes by three methods of measurement. Genotypes were selected for high $(\mathrm{H})$ and low $(\mathrm{L}) \mathrm{CO}_{2}$ exchange rate and yield levels (CER-yield).

hibited high $P R$ rates throughout the day, while low CER genotypes exhibited low rates. Differences between high and low GER genotypes were not as well defined for PR as for CER measurements, but a significantly positive correlation was found $(r=0.80)$ between PR and CER over the entire day. This direct relationship between CER and $P R$ supports the conclusion of Nelson et al. (1975b) and Laing et al. (1974) that these two processes are closely related metabolically, and selection for high CER will probably also select for high PR.

Leaf diffusive resistance among the four genotypes varied greatly early and late in the photoperiod when stomata were opening and closing (Fig. lc). However, they were similar during the remaining 11 hours of the photoperiod and did not account for the observed differences in CER. A slight increase in diffusive resistance of all genotypes was noted after 7 hours into the photoperiod, but this was not related to a change in CER. The L-H genotype had resistances of $\mathbf{3 . 3}$ $\mathrm{sec} / \mathrm{cm}$ between 8 and 9 hours into the photoperiod, which was significantly higher than the other genotypes. This was not related to a significant change in CER. In agreement with the present study, Frank and Barker (1976) indicated that calculated stomatal resistances ranging from 0.8 to $4.6 \mathrm{sec} / \mathrm{cm}$ in several $\mathrm{C}_{3}$ forage grass species were not controlling CER under conditions which allowed stomata to be fully open. Misken et al. (1972) reported that stomatal resistance of flag leaves of barley (Hordeum vulgare L.) increased from 1.27 to $1.92 \mathrm{sec} / \mathrm{cm}$ with decreasing stomatal frequency, but photosynthetic rates did not vary.

Pallas (1973) reported that several dicotyledonous species exhibited midday depressions and characteristic diurnal trends in CER, but in agreement with our study on the monocotyledon, tall fescue, the only monocatyledonous species in his study, bermudagrass (Cynodon dactylon L.), maintained a constant CER throughout the photoperiod. He also indicated that changes in stomatal diffusive resistance were not solely responsible for fluctuations in CER.

\section{PPFD Response}

Response of CER to PPFD for the four genotypes is presented as percent of maximum (Fig. 2). Genotype PPFD response curves were not significantly different $(\mathrm{p}<0.05)$ by any of the three methods of determination (Fig. 2a, b, c). Therefore, differences in photosynthetic rates between genotypes were due to inherent GER rather than differential PPFD saturation. Absolute values for the high CER genotypes were not as high in the field as in the growth chamber, but were significantly greater $(p<0.05)$ than the low CER genotypes. The field study reported here was conducted during early October and the lower air temperatures during this part of the season may have contributed to the relatively low CER.

The PPFD saturation (90\% of maximum CER) of tall fescue leaves for each measurement (Fig. 2d) occurred at approximately $1,200 \mu \mathrm{E} \mathrm{m}^{-2}$ sec $^{-1}$ suggesting that PPFD response was independent of previous irradiance history. This result was not expected because plants were grown under both field (up to 2,000 $\mu \mathrm{E}$ $\left.\mathrm{m}^{-2} \mathrm{sec}^{-1}\right)$ and growth chamber $\left(500 \mu \mathrm{E} \mathrm{M} \mathrm{M}^{-2} \mathrm{sec}^{-1}\right)$ conditions. Woledge (1971) reported tall fescue plants grown at high irradiance were capable of higher photosynthetic rates/unit leaf area and saturated at higher flux densities than similar plants grown at lower irradiance. However, similar CER responses to increasing illuminance were reported by Singh et al. (1974) for leaves of orchardgrass (Dactylis glomerata L.) plants grown under full sun and screens which reduced natural illumination by 30,50 , and $70 \%$. Wilson and Cooper (1969) also reported a nonsignificant genotype by light intensity interaction for photosynthesis in a 
growth chamber study of 10 ryegrass genotypes. Similar PPFD response curves have recently been reported for Panicum maximum Jacq. grown under controlled environment chamber, greenhouse, and field conditions by Ludlow and $\mathrm{Ng}$ (1976).

Photosynthetic fixation of $\mathrm{CO}_{2}$ contributes the majority of the total dry matter produced by a plant. A positive association between leaf photosynthesis and dry matter production would seem necessary if present methods of measuring photosynthesis are accurately estimating a plant's total $\mathrm{CO}_{2}$ fixation potential, and if other processes involved in deposition of dry matter are occurring with equal efficiency across genotypes. Results of this study indicated that genotypes selected for different maximum CER maintained those differences throughout the photoperiod. Some changes in leaf diffusive resistance were noted in the later part of the photoperiod, but were not associated with decreased CER.

The results of the studies reported here indicate that variation in the relationship between CER and yield in tall fescue can not be explained by the two hypotheses stated in the beginning of this paper. The four genotypes used in these experiments displayed similar CER responses to PPFD and similar PPFD saturation points when grown in two distinctly different environments and similar diurnal patterns of CER when measured on growth chamber grown plant material. Although these responses were similar, the genotypes consistently displayed rates of $\mathrm{CO}_{2}$ exchange that were consistant with their respective selection criteria. It does not appear that low CER, high yield genotypes have an advantage in total amount of $\mathrm{CO}_{2}$ fixed/unit leaf area under reduced PPFD conditions or at various times during the photoperiod which would explain how they are able to achieve their high yield characteristic. These experiments do, however, suggest that comparative CER of genotypes of tall fescue can be accurately estimated over a wide range of light conditions. Other factors are apparently expressing a dominating influence on the yield potential of the selected genotypes. Some of these factors might be dark respiration, dry matter distribution, and canopy architecture and development.

\section{REFERENCES}

1. Borrill, M., B. F. Tyler, and M. Kirby. 1974. Breeding of hybrid cocksfoot. Rep. Welsh Plant Breed. Stn. for 1973. p. 18-19.
2. Canvin, D. T. 1968. Photorespiration. Photosynthetica 2:318319.

3. Carlson, G. E., R. B. Pearce, D. R. Lee, and R. H. Hart. 1971. Photosynthesis and photorespiration in two clones of orchardgrass. Crop Sci. 11:35-37.

4. Epstein, E. 1972. Mineral nutrition of plants: Principles and perspective. John Wiley and Sons, Inc. New York, N.Y.

5. Frank, A. B., and R. E. Barker. 1976. Rates of photosynthesis and transpiration and diffusive resistance of six grasses grown under controlled conditions. Agron. J. 68:487-490.

6. Heichel, G. H. 1971. Confirming measurements of respiration and photosynthesis with dry matter accumulation. Photosynthetica $5: 93-98$.

7. Kanemasu, E. T., G. W. Thurtell, and C. G. Tanner. 1969 Design, calibration, and field use of a stoniatal diffusion porometer. Plant Physiol. 44:881-885.

8. Laing, W. A., W. L. Ogren, and R. H. Hageman. 1974 Regulation of soybean net photosynthetic $\mathrm{CO}_{2}$ fixation by the interaction of $\mathrm{CO}_{3}, \mathrm{O}_{2}$, and ribulose 1,5-diphosphate carboxylase. Plant Physiol. 54:678-685.

9. Ludlow, M. M., and T. T. Ng. 1976. Photosynthetic light response curves of leaves from controlled environment facilities, glasshouse, or outdoors. Photosynthetica 10:457-462.

10. Miskin, E. E., D. C. Rasmusson, and D. N. Moss. 1972. Inheritance and physiological effects of stomata frequency in barley. Crop Sci. 12:780-783.

11. Nelsou, C. J., K. H. Asay, and G. L. Horst, 1975a. Relationship of leaf photosynthesis to forage yield of tall fescue. Crop Sci. 15:476-478.

12. - - - - _- and E. S. Hilderbrand. 1974. Field measurement of photosynthesis in a forage grass breeding program. Crop Sci. 14:26-28.

13.,------- , and L. D. Patton. 1975b. Photosynthetic responses of tall fescue to selection for longevity below the $\mathrm{CO}_{2}$ compensation point. Crop Sci. 15:629-633.

14. Pallas, J. E. 1973. Diurnal change in transpiration and daily photosynthetic rate of several crop plants. Crop Sci. 13:82-84.

15. Rhodes, I. 1972. Yield, leaf area index, and photosynthetic rate of some perennial ryegrass (Lolium perenne $\mathbf{L}$.) selections. J. Agric. Sci. (Cambridge) 78:509-511.

16. - - 1 1973. Relationship between canopy structure and productivity in herbage grasses and its implications for plant breeding. Herb. Abstr. 43:129-133.

17. Singh, M., W. L. Ogren, and J. M. Widholm. 1974. Photosynthetic characteristics of $\mathrm{C}_{3}$ and $\mathrm{C}_{4}$ plant species grown under different light intensities. Crop Sci. 14:563-566.

18. Treharne, K. J., and C. F. Eagles. 1970. Effect of temperature on photosynthetic activity of climatic races of Dactylis glomerata. Photosynthetica 4:107-117.

19. Wilson, D., and J. P. Cooper. 1969. Effect of light intensity and $\mathrm{CO}_{2}$ on apparent photosynthesis and its relationship with leaf anatomy in genotypes of Lolium perenne L. New Phytol. 68:627-644.

20. - - - , and - - 1970. Effect of selection for mesophyll cell size on growth and assimilation in Lolium perenne $\mathrm{L}$. New Phytol. 69:233-245.

21. Woledge, J. 1971. The effect of light intensity during growth on the subsequent rate of photosynthesis of leaves of tall fescue (Festuca arundinacea Schreb.). Ann Bot. 35:311-322. 